$\frac{\text { Applied Sciences in Dentistry }}{\text { JOURNAL }}$

\title{
EDITORIAL
}

\section{INVESTIGACIÓN CUALITATIVA}

La investigación cualitativa por definición se orienta a la producción de datos descriptivos, como son las palabras y los discursos de las personas, quienes los expresan de forma hablada y escrita, además, de la conducta observable (Taylor, S.J. y Bogdan R.,1986).

Luego, la principal interrogante epistemológica que se plantea este tipo de investigación se orienta a cuestionar el conocimiento objetivo de la "realidad" que estudia, en tanto los relatos y el comportamiento se expresan sobre la base de lo que cada sujeto conoce a partir de su experiencia subjetiva del y con el mundo. En esta línea, la perspectiva Constructivista Radical de la investigación cualitativa instala la idea de la imposibilidad de un conocimiento objetivo de la "realidad", puesto que "todo acto de conocimiento implica una intervención activa de la persona que observa, que se convierte así, en "constructor" de la realidad que percibe y no un receptor pasivo de estímulos externos" (Von Glasersfeld, 1995).

Esta condición de la "realidad como construcción inventada" que interesa a la investigación cualitativa, es producto de la perspectiva, de los instrumentos cognitivos y del lenguaje que permite percibir y comunicar a los sujetos, por lo que el conocer es un proceso de adaptación que organiza las experiencias de estos de un modo eficaz.

El desafío, entonces, de la investigación cualitativa es acceder a esa "realidad inventada" teniendo presente, según Bateson (1976), el papel del observador sobre esa "realidad" observada. De esta forma, este método es relevante cuando se investigan fenómenos sociales complejos que son difíciles de capturar desde la perspectiva cuantitativa, como son las perspectivas de las personas en torno a sus relaciones, creencias, hábitos y valores (Bedregal et al, 2017). 
La investigación cualitativa, así, permite comprender la profundidad de un fenómeno a partir de la mirada de los actores sociales, la que se integra a los modelos explicativos cuantitativos, como es el caso de los fenómenos de la salud, donde la explicación de ellos no está completa sin la perspectiva de los sujetos que portan la salud/enfermedad.

Las fases metodológicas son similares a la investigación cuantitativa: Preparatoria o de Diseño; Trabajo de campo o Recogida de la información; Fase Analítica o Discusión; e Informativa o de Difusión. No obstante, dichas similitudes, la investigación cualitativa varía en la definición del objeto de estudio, el que está compuesto de relatos y discursos que informan de las experiencias, creencias, valores, etc. de los sujetos muestrales; como en la flexibilidad metodológica en que las fases no tienen inicio ni fin claros, sino que se superponen y entremezclan de conformidad a las exigencias del objeto de estudio. Del mismo modo, el rol del marco teórico es secundario en el diseño del proceso, porque se estima que en esta etapa cargaría de preconceptos la subjetividad de los relatos; y, finalmente, el rol del investigador cualitativo se estima es el instrumento más importante en el desarrollo de la investigación porque va tomando las decisiones que van delimitando el proceso.

La Metodología de la Investigación Cualitativa en Salud ha establecido un enfoque diferenciador que se centra en el estudio sistemático de la experiencia cotidiana y la definición de la salud como algo cultural (Conde F, Pérez C., 1995) bajo el argumento que la mayoría de los aspectos de la salud son de naturaleza social, por lo cual, el concepto de salud -enfermedad se encuentra asociado a creencias y valoraciones entre otros elementos.

En el campo de la investigación cualitativa en Odontología, Oliva, P. et al (2014) señalan que en los últimos años ha tenido un desarrollo incipiente, "con un número limitado de publicaciones al respecto (36 publicaciones que cumplían con todos los criterios)". Y los estudios que la han incorporado se organizan en torno a 3 ejes principales: la percepción y comprensión de la naturaleza de procesos sociales y cotidianos asociados con patologías o condiciones orales. En segundo lugar, se establecen discursos que emiten explicaciones que permiten conocer por qué se producen las patologías orales y cuáles son los distintos factores intersubjetivos asociados al tratamiento odontológico; y, en tercer lugar, los discursos de los contenidos, que permite al investigador odontólogo adecuar el procedimiento con el objetivo de examinar la dinámica del funcionamiento de los fenómenos socioculturales que está estudiando (Oliva, P. et al, 2014).

Dado lo señalado, Applied Sciences in Dentistry busca ampliarse a todas las formas de dar cuenta de manera más integral y completa posible del fenómeno y proceso de la salud bucodentaria, por lo que extiende una amplia invitación a los investigadores a enviarnos ponencias que incorporen este método de investigación. 